\title{
THE MULTIVARIATE STATISTICAL ANALYSIS OF ABIOTIC PARAMETERS OF THE LAKE TANGANYIKA SUB CATCHMENT
}

\author{
H. H. Nkotagu \\ Geology Department, University of Dar es Salaam, P.O. Box 35052, Dar es Salaam \\ *e-mail: hudson@udsm.ac.tz
}

\begin{abstract}
Results from multivariate statistical analysis of abiotic parameters conducted during the dry season at 20 accessible sites on 8 rivers, 2 lakes and a dam covering the Lake Tanganyika sub catchment are discussed. Standard methods were used to determine the levels of abiotic parameters from water samples. Physical parameters including DO, EC, Eh, turbidity, temperature, $\mathrm{pH}$ and secchi transparency were measured in situ while chlorophyll a was determined in the laboratory. Nutrients such as $\mathrm{NO}_{3}^{-}, \mathrm{SiO}_{2}, \mathrm{PO}_{4}^{3-}$ and $\mathrm{Fe}^{2+}$ were determined along with $\mathrm{HCO}_{3}^{-}$. Factor analysis resulted in four factors including increased primary productivity, redox conditions, dissolution, and reduction processes. Processes including dissolution, diffusion, adsorption, absorption, nitrification, denitrification, mixing and reduction along with the anthropogenic activities, increased photosynthetic activity of algae and the geomorphology of the ecosystems contribute to the variation of the abiotic parameters. It is recommended that quantification of river flows, sediment load and nutrient budget at various sampling points be determined seasonally for proper evaluation of the hydrologic and limnological functioning of the ecosystem.
\end{abstract}

Keywords: Multivariate statistics, Malagarasi Wetland, Abiotic parameters

\section{INTRODUCTION}

The limnology of tropical rivers and lakes along with dams has recently received a paramount and growing attention due to pressures from land, atmospheric, and riverine inputs. The Lake Tanganyika sub-catchment includes the Malagarasi-Muyovozi Wetland Ecosystem in the Western Tanzania, a polymictic fresh water ecosystem designated as first Tanzanian Ramsar site and the world's $1024^{\text {th }}$ Ramsar site since 2000 (Nkotagu and Athuman, 2008).

It is estimated that during the last 10 years the depth of the wetland has systematically been reduced to a maximum of about $2 \mathrm{~m}$. The wetland is located in western Tanzania about $200 \mathrm{~km}$ NE of Lake Tanganyika as shown in figure 1. The wetland is characterized with biodiversity including varieties of flora and fauna such as fish of which 50 species are known with some being endemic, crocodiles, hippopotamus and other microorganisms.

These tropical ecosystems support the life of many people and other organisms within the Lake Tanganyika sub catchment and hence form a unique ecosystem. However, very little information on the assessment of limnological data in this sub-catchment is known.

The present study therefore trucked down the multivariate statistical analysis of the abiotic parameters from various surface water bodies including rivers, lakes and a dam in the Lake Tanganyika sub-catchment as detected at various accessible points.

\section{MATERIALS AND METHODS}

\section{Study area}

The study was conducted for six weeks during the dry season commencing September to October 2004. The study covered the rivers Igombe, Lugufu, Luiche, Makere, Malagarasi, Moyowosi, Ruchugi, and Ugalla along with the lakes Sagara and Nyamagoma as well as the Igombe Dam within the eastern side of the Lake Tanganyika sub-catchment (Fig. 1).

\section{Geology of the study area}

The river is located predominantly at the mesoproterozoic sandstones of about 1,200 million years old with lithology covering shales, quartzites, dolomitic limestones, gneisses and basalts along with quaternary sediments at some places (Pina et al., 2004). These rocks are exposed differently at various 
places along the riverbed thus influencing the geomorphologic of the river behaviour accordingly. Shallow portions of the river are observed to be underlain by hard quartzite, quartztic sandstones and or gneissic rocks that resist both chemical and physical weathering. However, the deepest parts of the river are observed to be dominated by dolomitic limestones and basalts as bedrocks that are easily chemically weathered. The river is located within the western arm of the Eastern African Rift System therefore its geomorphologic behaviour is essentially both geologically and tectonically controlled.

\section{Sampling}

Sampling sites were initially decided basing on water depths as measured at various positions on the rivers, lakes and the dam using a SCUBA device. Water samples were collected at selected depth intervals up to maximum depths in half and one-litre plastic bottles filled to the brim using a 2-1 water sampler. However, at some rivers, sampling was conducted in a horizontal transect across the river at three positions including the centre, right and left banks.

Aliquots of $400 \mathrm{ml}$ and $800 \mathrm{ml}$ of each water sample were filtered using pore size glass fibre $47 \mathrm{~mm}$ size filter papers. The filtrate aliquots were transported on ice to the laboratory for Silica $\left(\mathrm{SiO}_{2}\right)$, Nitrate $\left(\mathrm{NO}_{3}{ }^{-}\right)$, Phosphate $\left(\mathrm{PO}_{4}{ }^{3-}\right)$ and Iron $\left(\mathrm{Fe}^{2+}\right)$ determinations. The remaining unfiltered water samples were similarly transported to the laboratory for alkalinity determination. Filters were placed into a test tube on to which $10 \mathrm{ml}$ of $90 \%$ ethanol were added. The test tubes were then wrapped with aluminium foil, marked and stored overnight in a cooler at $4^{\circ} \mathrm{C}$ ready for chlorophyll $a$ readings the following day.

In situ physical parameters including electrical conductivity (EC), dissolved oxygen (DO), $\mathrm{pH}$ and temperature were measured at each sampling site using a Multi Probe meter 340i model. In addition, turbidity and water transparency were also measured using a $\mathrm{HACH}$ turbidimeter $2100 \mathrm{P}$ model and a $20 \mathrm{~cm}$ diameter Secchi disk respectively.

\section{Laboratory work}

The filtered water samples were stored at $4^{\circ} \mathrm{C}$ before analysis. Fluorescence readings for chlorophyll $a$ were taken using a Fluorometer before and after acidifying the sample residues with $0.1 \mathrm{~N} \mathrm{HCl}$. The absorbance readings were then converted into concentrations as chlorophyll $a$ using the formula according to McIntyre (2004 unpublished data):

Chl $a\left(\mu \mathrm{g} 1^{-1}\right)=0.003 \times\left(\mathrm{F}_{\text {before acid }}-\mathrm{F}_{\text {after acid }}\right) \times$ Ethanol Extraction Volume (ml)/Volume of Filtered Water (L)

Unfiltered water samples were tested for alkalinity using a titrimetric method with $0.1 \mathrm{~N}$ $\mathrm{HCl}$ and results expressed as $\mathrm{HCO}_{3}^{-}\left(\mathrm{mg} \mathrm{l}^{-1}\right)$ as explained by APHA (1998). Nutrients including $\mathrm{SiO}_{2}, \mathrm{NO}_{3}{ }^{-}, \mathrm{PO}_{4}{ }^{3-}$ and $\mathrm{Fe}^{2+}$ were determined from the filtered water samples using a HACH Spectrophotometer DR/2010 model according to HACH (2002).

\section{Data analysis and interpretation}

The data were analysed by the SPSS 11.0 package and other statistical analyses following Davis (1986).

\section{RESULTS AND DISCUSSION}

\section{Descriptive Statistics}

The results for the descriptive statistics of the abiotic parameters (Tab. 1) indicate high mean salinity from the 64 samples. This is attributed to increased dissolution of minerals and washing in nutrients from anthropogenic sources (Nkotagu and Athuman, (2008) Accepted. However, the mean $\mathrm{pH}$ of 7.72 is a good indicator that the water is well buffered as shown by the high mean alkalinity $(59.726 \mathrm{mg}$ $\left.1^{-1}\right)$.

The mean levels of nutrients show a significant variation consequent to the photosynthetic activities of algae and the anthropogenic activities in the cathment area along with several processes such as absorption, adsorption, nitrification, denitrification in the water column under redox conditions. 


\section{Correlation Analysis}

The results from the correlation matrix between the abiotic parameters (Tab. 2) using the two tailed Pearson correlation show positive and negative correlation between any two parameters consequent to ecological and geomorphologic differences. Temperature correlates positively with $\mathrm{pH}$, weakly with transparency, salinity, $\mathrm{HCO}_{3}^{-}$, and $\mathrm{SiO}_{2}$. This indicates that warm surface waters result in increased photosynthetic activity as indicated by high abundance of chlorophyll $a$ and dissolved oxygen and thus leading to increased consumption of $\mathrm{CO}_{2}$.

The positive correlation between $\mathrm{pH}$ and the $\mathrm{HCO}_{3}{ }^{-}$supports the observed relationship. High positive correlation between chlorophyll $a$ and turbidity suggest primary productivity to be the main cause of the later in many parts of the study area. This suggestion is supported by the high negative correlation between chlorophyll $a$ and transparency. The positive correlation among the nutrients $\mathrm{SiO}_{2}, \mathrm{PO}_{4}{ }^{3-}$ and $\mathrm{NO}_{3}{ }^{-}$ indicates that these nutrients have a common source (mainly anthropogenic). The redox potential correlates negatively with dissolved oxygen, $\mathrm{pH}$, temperature, salinity and alkalinity consequent to redox conditions.

\section{Factor Analysis}

Factor analysis (Thurstone, 1931) is used to present the structure of studied data by means of their grouping and classification as well as for space dimension reduction of the analyzed parameters.

The Principal Component Analysis (PCA) and Varimax rotation with Kaiser Normalization (Kaiser 1958) were used to obtain results for the factor analysis. Four rotated factors were extracted (Tab. 3) as the controlling measures to the abiotic parameters within the subcatchment.

\section{Factor 1}

Factor 1 is highly positively loaded with $\mathrm{NO}_{3}{ }^{-}$, DO, chlorophyll $a$ and turbidity and negatively loaded with water transparency. This factor may generally be referred to as a primary productivity factor showing that water transparency was low due to high turbidity caused by the increased photosynthetic algae as indicated by a positive relationship between chlorophyll $a$ and turbidity. The concentration of $\mathrm{NO}_{3}{ }^{-}$increased with DO and chlorophyll $a$ indicating that primary productivity increases with increased nutrient concentration. .

\section{Factor 2}

Factor 2 is highly loaded with DO, pH, temperature and salinity and showed that the $\mathrm{DO}$ relates directly to the $\mathrm{pH}$, temperature and the salinity of water. However, these parameters in this factor are observed to relate negatively with the redox potential of water showing that the redox conditions affect the oxygen levels leading to high $\mathrm{CO}_{2}$ in the water as a result lowering the $\mathrm{pH}$ of water.

\section{Factor 3}

The factor is highly positively loaded with $\mathrm{PO}_{4}{ }^{3-}, \mathrm{SiO}_{2}, \mathrm{NO}_{3}{ }^{-}$, temperature and salinity along with the alkalinity of water. This can be thought as a generalized dissolution process factor indicating that the dissolution of $\mathrm{HCO}_{3}{ }^{-}$, $\mathrm{PO}_{4}{ }^{3-}, \mathrm{SiO}_{2}$ and $\mathrm{NO}_{3}{ }^{-}$as facilitated by high temperature through water mass overturns lead to high salinity.

\section{Factor 4}

This factor is positively loaded with $\mathrm{Fe}^{2+}$ and water depth. The factor may be referred to as a reduction process factor. This indicates that the reduction of ferric iron to ferrous iron increases with increasing depth of water.

\section{Cluster Analysis}

Cluster analysis (Tryon, 1939) combines different algorithms for classification. In this study three major clusters of abiotic parameters were resulted (Fig. 2). The clustering indicates that parameters are clustered according to biological process favouring turbidity, $\mathrm{NO}_{3}{ }^{-}$as a favoured nutrient in the process and dissolved oxygen.

The second cluster favours salinity to be primary due to $\mathrm{HCO}_{3}{ }^{-}, \mathrm{pH}, \mathrm{SiO}_{2}, \mathrm{PO}_{4}{ }^{3-}$ and water temperature implying that dissolution of anthropogenic salts under favourable 
temperatures and $\mathrm{pH}$ may be responsible for the salinity of the water in the area.

Finally, the third cluster involves transparent, depth, Eh and $\mathrm{Fe}^{2+}$ indicating that the depth of water as expected influences the concentration of the above parameters. Light penetration decreases with depth due increased chlorophyll $a$ and suspended sediments. However, Eh and $\mathrm{Fe}^{2+}$ increase with depth due to reduction process.

\section{CONCLUSIONS AND RECOMMENDATIONS}

The data in the present study conclude that the variation of the abiotic parameters at the Lake Tanganyika sub-catchment is controlled by factors including increased primary productivity, redox conditions, dissolution, nitrification, denitrification, mixing and reduction along with anthropogenic activities.

The suspended sediments close to the Malagarasi delta and non-point pollutants such as fertilizers at the Kasulu-Kibondo Bridge and animal excreta near Igombe dam could also be contributing heavily to the fluctuation of nutrient within the sub- catchment.

It is recommended that future work focuses on the statistical approaches in the quantification of flow, sediment load and nutrient budget at various points along the rivers, lakes and the dam in both dry and rain seasons in order to fully understand the hydrological and limnological functioning of the Lake Tanganyika sub-catchment.

\section{ACKNOWLEDGEMENTS}

The author is grateful to the financial support from the Royal Geographical Society (UK) and the US National Geographical Society (NGS). The University of Dar Es Salaam and the Ministry of Natural Resources and Tourism provided the permission for this work. The Tanzania Fisheries Research Institute (TAFIRI) in Kigoma, the Nyanza Project and the rest of the crew are greatly acknowledged for their assistance and cooperation during the fieldwork as well as in the laboratory.

\section{NOMENCLATURE}

SPSS 11.0 = Statistical Package for Social

Scientists version 11.0

$\mathrm{F}=$ Fluorescence of the sample, which is equivalent to the absorbance on a Spectrophotometer and

Chl $a=$ Chlorophyll $a$ in $\mu \mathrm{g}^{-1}$.

\section{REFERENCES}

APHA, 1998. (American Public Health Association), Standard Methods for Examination of Water and Wastewater. $20^{\text {th }}$ ed. American Public Health Association. Washington, DC, 10-30, p.

Appelo, C.A.J, and Postma,D., 1994. Geochemistry, groundwater and pollution, $2^{\text {nd }}$ ed., A.A. Balkema, Rotterdam, The Netherlands. $536 \mathrm{p}$.

Cohen, A.S. 2003. Paleolimnology: The History and Evolution of Lake Systems, Oxford University Press, Inc., New York, $500 \mathrm{p}$.

Davis, J.C., 1986. Statistics and Data Analysis in Geology, $2^{\text {nd }}$ ed., John Wiley and Sons, $646 \mathrm{p}$.

HACH 2002. Company, Water Analysis Handbook, $4^{\text {th }}$ ed., Loveland. Colorado, USA , 1260p.

Horne, A.J., and C.R. Goldman, 1994. Limnology, $2^{\text {nd }}$ ed., McGraw-Hill, Inc., USA, $576 \mathrm{p}$.

Kaiser, H.F., 1958. The varimax criterion for analytical rotation in factor analysis, Psychometrika, Vol. 23, p. 187-200.

Nkotagu, H.H., and Athuman, C.B.,2008. The Limnogeology of the Lakes Sagara and Nyamagoma, (2008) THE Vol. 13, pp 1221.

Nkotagu, H.H., and Athuman, C.B., 2008. The Limnology of the Lake Tanganyika Sub Catchment, Tanz. J. Sci., (Accepted).

Pina, P., Muhongo, S., Le Goff, E., Mcharo, B.A., Deschamps,Y., Milesi, J.P., Vinanger, P., and Ralay, F., 2004. Geology and Mineral map of Tanzania (Scale 1: 2,000,000), BRGM-UDSMGST.

Thurstone, L., 1931. Multiple factor analysis, Psychological Review, Vol. 38, p. 406427. 
Tryon, R., 1939. Cluster Analysis, Ann Arbor, Ml: Edwards Brothers.

Wetzel, R.G., and G.E. Likens, 1990. Limnological Analyses, $2^{\text {nd }}$ ed. SpringerVerlag, New York, $391 \mathrm{p}$.
Wetzel, R.G., 2001. Limnology: Lake and River Ecosystem, $3^{\text {rd }}$ ed., Academic Press, 1006 pp.

\section{List of tables}

Table 1.0: Descriptive statistics of abiotic parameters

\begin{tabular}{|c|c|c|c|c|c|}
\hline Parameter & $\mathbf{N}$ & Minimum & Maximum & Mean & $\begin{array}{c}\text { Std. } \\
\text { Deviation }\end{array}$ \\
\hline $\mathrm{EC}\left(\mu \mathrm{S} \mathrm{cm}^{-1}\right)$ & 64 & 32.00 & 544.00 & 294.793 & 127.445 \\
\hline $\mathrm{HCO}_{3}^{-}\left(\mathrm{mg} \mathrm{l}^{-1}\right)$ & 64 & 18.30 & 140.30 & 59.726 & 26.770 \\
\hline Temp $\left({ }^{\circ} \mathrm{C}\right)$ & 64 & 20.23 & 27.28 & 25.254 & 1.491 \\
\hline Turb (NTU) & 64 & 2.13 & 68.52 & 16.800 & 18.039 \\
\hline Chl $a\left(\mu \mathrm{g}^{-1}\right)$ & 64 & 0.01 & 144.18 & 16.365 & 37.194 \\
\hline $\mathrm{SiO}_{2}\left(\mathrm{mg} \mathrm{l}^{-1}\right)$ & 64 & 2.70 & 35.30 & 14.271 & 5.532 \\
\hline $\mathrm{pH}$ & 64 & 6.39 & 8.52 & 7.719 & 0.518 \\
\hline $\mathrm{DO}\left(\mathrm{mg} \mathrm{l}^{-1}\right)$ & 64 & 0.08 & 9.16 & 4.652 & 2.387 \\
\hline $\mathrm{NO}_{3}^{-}\left(\mathrm{mg} \mathrm{l}^{-1}\right)$ & 64 & 0.44 & 2.64 & 1.196 & 0.549 \\
\hline Trans (m) & 64 & 0.13 & 1.93 & 1.041 & 0.616 \\
\hline Depth (m) & 64 & 0.00 & 4.00 & 0.970 & 1.034 \\
\hline $\mathrm{PO}_{4}^{3-}\left(\mathrm{mg} \mathrm{l}^{-1}\right)$ & 64 & 0.01 & 0.16 & 0.045 & 0.034 \\
\hline $\mathrm{Fe}^{2+}\left(\mathrm{mg} \mathrm{l}^{-1}\right)$ & 64 & -0.01 & 0.02 & 0.003 & 0.008 \\
\hline $\mathrm{Eh}(\mathrm{mV})$ & 64 & -101.25 & 30.00 & -51.850 & 32.488 \\
\hline
\end{tabular}

Table 2.0: Correlation matrix showing levels of relationships between parameters

\begin{tabular}{|c|c|c|c|c|c|c|c|c|c|c|c|c|c|c|}
\hline & Trans & Depth & Turb & $\mathbf{p H}$ & DO & Temp & EC & $\mathbf{E h}$ & $\mathrm{HCO}_{3}$ & ${ }_{3} \mathrm{SiO}_{2}$ & $\mathrm{NO}_{3}$ & $\mathrm{PO}_{4}$ & $\mathrm{Fe}^{2+}$ & Chl $a$ \\
\hline Trans & 1 & & & & & & & & & & & & & \\
\hline Depth & .368 & 1 & & & & & & & & & & & & \\
\hline Turb & -.627 & -.087 & 1 & & & & & & & & & & & \\
\hline pH & .169 & -.019 & .055 & 1 & & & & & & & & & & \\
\hline DO & -.211 & .027 & .261 & .427 & 1 & & & & & & & & & \\
\hline Temp & .392 & .063 & -.084 & .511 & .287 & 1 & & & & & & & & \\
\hline EC & .417 & .193 & -.193 & .575 & .087 & .642 & 1 & & & & & & & \\
\hline Eh & -.180 & .002 & -.055 & -.983 & -.423 & -.467 & -.546 & 1 & & & & & & \\
\hline $\mathrm{HCO}_{3}$ & -.084 & .096 & .181 & .451 & .256 & .496 & .708 & -.410 & 1 & & & & & \\
\hline $\mathrm{SiO}_{2}$ & -.166 & -.178 & .247 & .367 & .365 & .433 & .465 & -.327 & 7.634 & 1 & & & & \\
\hline $\mathrm{NO}_{3}$ & -.534 & -.272 & .454 & .081 & .264 & .050 & .056 & -.058 & 8.391 & .404 & 1 & & & \\
\hline $\mathrm{PO}_{4}$ & -.303 & -.201 & .228 & .133 & .088 & .086 & .331 & -.080 & 0.512 & .439 & .405 & 1 & & \\
\hline $\mathrm{Fe}^{2+}$ & -.218 & .063 & .142 & -.241 & .063 & -.239 & -.149 & .213 & -.057 & -.088 & -.100 & -.049 & 1 & \\
\hline Chl $a$ & -.431 & -.065 & .736 & .092 & .426 & .207 & -.024 & -.065 & 5.323 & .431 & .576 & .301 & -.072 & 1 \\
\hline
\end{tabular}


Table 3.0: Rotated component matrix ${ }^{\mathrm{a}}$ showing factor loadings with abiotic parameters

\begin{tabular}{|c|c|c|c|c|}
\hline \multirow[b]{2}{*}{ Parameter } & \multicolumn{4}{|c|}{ Component } \\
\hline & 1 & 2 & 3 & 4 \\
\hline Turb (NTU) & 0.853 & & & \\
\hline Trans (m) & -0.823 & 0.269 & & 0.208 \\
\hline Chl $a\left(\mu \mathrm{g} \mathrm{1^{-1 }}\right)$ & 0.786 & 0.146 & 0.245 & \\
\hline $\mathrm{NO}_{3}{ }^{-}\left(\mathrm{mg} \mathrm{l}^{-1}\right)$ & 0.652 & & 0.381 & -0.287 \\
\hline $\mathrm{Eh}(\mathrm{mV})$ & & -0.914 & -0.159 & 0.117 \\
\hline $\mathrm{pH}$ & & 0.908 & 0.217 & -0.140 \\
\hline $\mathrm{DO}\left(\mathrm{mg} \mathrm{l}^{-1}\right)$ & 0.506 & 0.605 & & 0.181 \\
\hline Temp $\left({ }^{\circ} \mathrm{C}\right)$ & -0.167 & 0.588 & 0.489 & \\
\hline $\mathrm{HCO}_{3}^{-}\left(\mathrm{mg} \mathrm{l}^{-1}\right)$ & 0.172 & 0.288 & 0.842 & 0.111 \\
\hline $\mathrm{EC}\left(\mu \mathrm{S} \mathrm{cm} \mathrm{cm}^{-1}\right)$ & -0.326 & 0.445 & 0.757 & 0.111 \\
\hline $\mathrm{PO}_{4}{ }^{3-}\left(\mathrm{mg} \mathrm{l}^{-1}\right)$ & 0.281 & -0.148 & 0.712 & -0.238 \\
\hline $\mathrm{SiO}_{2}\left(\mathrm{mg} \mathrm{l}^{-1}\right)$ & 0.328 & 0.288 & 0.668 & -0.112 \\
\hline Depth (m) & -0.234 & & & 0.816 \\
\hline $\mathrm{Fe}^{2+}\left(\mathrm{mg} \mathrm{l}^{-1}\right)$ & 0.221 & -0.271 & -0.104 & 0.547 \\
\hline
\end{tabular}

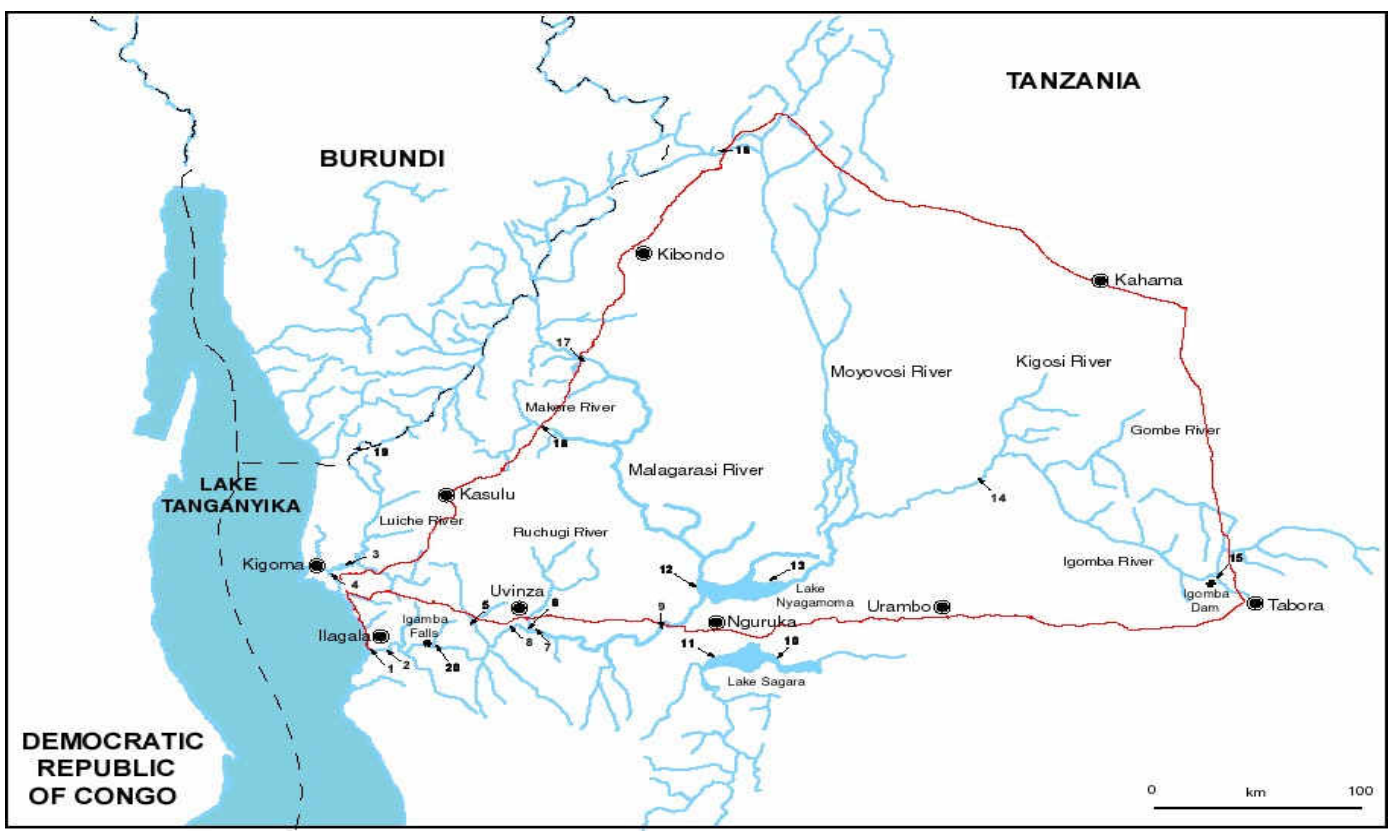

Fig. 1.0: The Lake Tanganyika sub catchment showing the sampling sites 1 to 20 .

Key: 1=Malagarasi River at the Delta, $2=$ Malagarasi River at the Ilagala Ferry, $3=$ Luiche River at the Kigoma-Kasulu Bridge, 4=Luiche River at the Delta in Ujiji, 5=Lugufu River at Jackobsen's Farm, 6=Ruchugi River at the KigomaUvinza Bridge, 7=Malagarasi River at the Nyanza Salt Mine, 8=Malagarasi River at the Uvinza-Mpanda Bridge, 9=Malagarasi River at the Uvinza-Nguruka Bridge, 10=Lake Sagara at Amerika,

11=Ugalla River at Katumba, 12=Moyovosi River mouth at the Lake Nyamagoma, 13=Igombe River at Mtega in Kaliua, 14=Igombe River at Uyowa in Urambo, 15=Igombe Dam in Tabora, 16=Moyovosi River at the Kagera-Kigoma Bridge, 17=Malagarasi River at the Kasulu-Kibondo Bridge, 18=Makere River at the Bridge, 19=Malagarasi River at the Burundi-Tanzania Border, 20=Malagarasi River at the Igamba Water Fall 


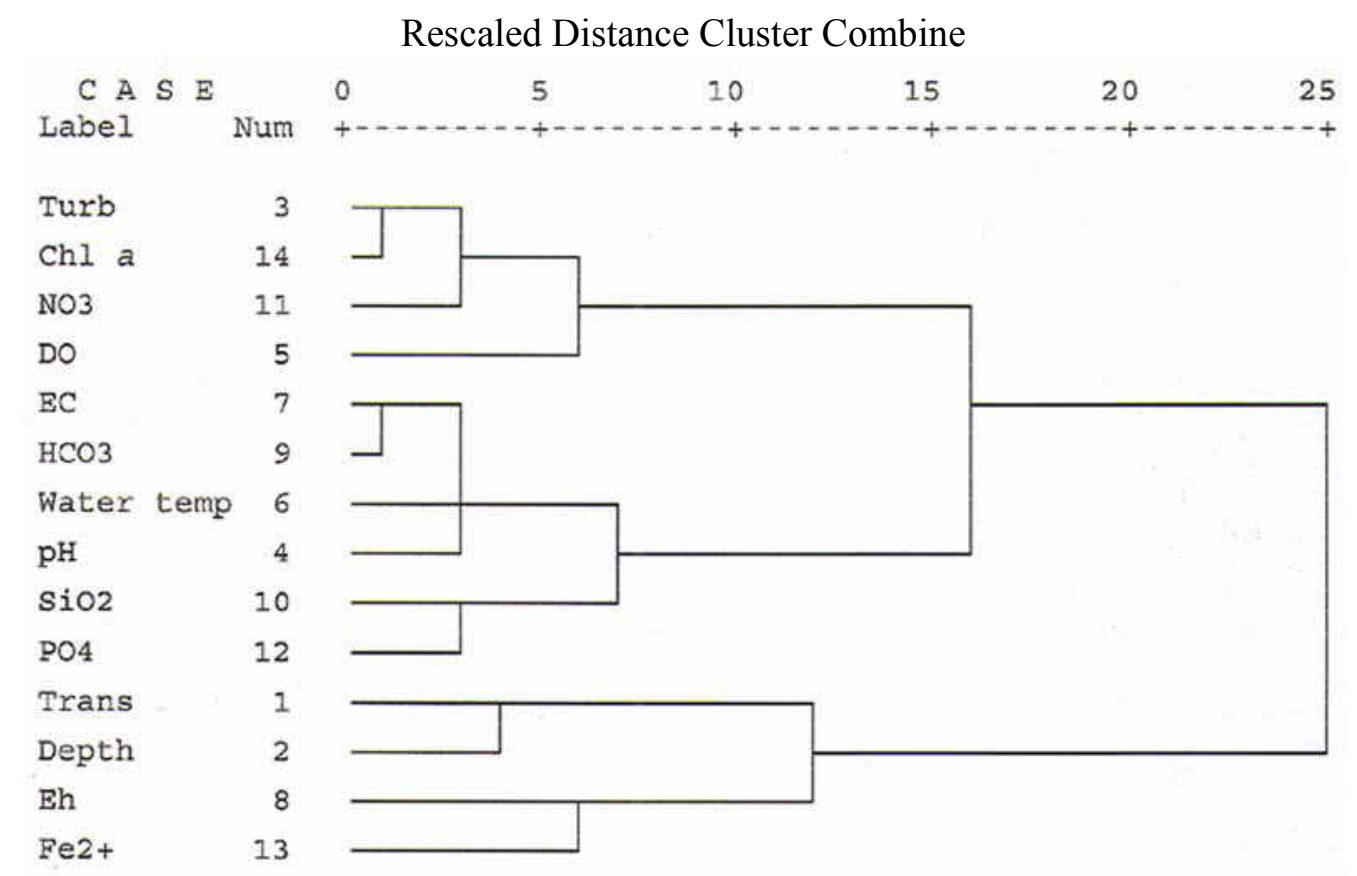

Fig. 2.0: The dendogram results for the sampling sites 